\title{
Fe-EDDHA Alleviates Chlorosis in 'Concord' Grapevines Grown at High pH
}

\author{
Brandon R. Smith and Lailiang Cheng ${ }^{1}$ \\ Department of Horticulture, Cornell University, 134A Plant Science, Ithaca, \\ NY 14853
}

\section{Additional index words. active $\mathrm{Fe}, \mathrm{CO}_{2}$ assimilation, $\mathrm{Fe}$ deficiency, Vitis labruscana}

\begin{abstract}
Concord' grapevines (Vitis labruscana Bailey) can readily develop iron deficiency-induced leaf chlorosis when grown on calcareous or high $\mathrm{pH}$ soils. Iron (Fe) chelates are often applied to the soil to remedy chlorosis but can vary in their stability and effectiveness at high pH. We transplanted own-rooted 1-year-old 'Concord' grapevines into a peat-based medium adjusted to $\mathrm{pH} 7.5$ and fertigated them with $0,0.5,1.0,2.0$, or $4 \mathrm{mg} \cdot \mathrm{L}^{-1} \mathrm{Fe}$ from Fe-EDDHA [ferric ethylenediamine di (o-hydroxyphenylacetic) acid] to determine the effectiveness of this Fe chelate for alleviating Fe deficiency-induced chlorosis at high $\mathrm{pH}$. Vines were sampled midseason for iron, chlorophyll, $\mathrm{CO}_{2}$ assimilation, and photosystem II quantum efficiency (PSII) and at the end of the season for leaf area, dry weight, and cane length. We found that leaf total Fe concentration was similar across all treatments, but active $\mathrm{Fe}$ (extracted with $0.1 \mathrm{~N} \mathrm{HCl}$ ) concentration increased as the rate of Fe-EDDHA increased. Chlorophyll concentration increased curvilinearly as applied $\mathrm{Fe}$ increased and was highly correlated with active $\mathrm{Fe}$ concentration. $\mathrm{CO}_{2}$ assimilation, stomatal conductance, and PSII were very low without any supplemental $\mathrm{Fe}$ and increased rapidly in response to $\mathrm{Fe}$ application. Total leaf area, foliar dry weight, and cane length all increased as Fe application increased to $1 \mathrm{mg} \cdot \mathrm{L}^{-1} \mathrm{Fe}$, but above this rate, a further increase in Fe did not significantly increase growth. Our results demonstrate that Fe-EDDHA is very effective in alleviating Fe deficiency-induced leaf chlorosis in 'Concord' grapevines grown at high $\mathrm{pH}$, which provides a foundation for continuing research related to the optimum rate and timing of application of Fe-EDDHA in 'Concord' vineyards on calcareous soils. Compared with total $\mathrm{Fe}$, leaf "active $\mathrm{Fe}$ " better indicates the actual Fe status of 'Concord' vines.
\end{abstract}

'Concord' grapevines (Vitis labruscana Bailey) are native to the northeastern United States (Schofield, 1988) and are tolerant of the acidic soils that characterize the region. As soil $\mathrm{pH}$ increases and iron $(\mathrm{Fe})$ becomes less available, own-rooted 'Concord' grapevines can readily develop Fe deficiencyinduced leaf chlorosis. In 'Concord' vineyards where calcareous or high $\mathrm{pH}$ soils predominate such as in Washington State, leaf chlorosis can be a limiting factor in production (Davenport and Stevens, 2006).

Iron is a key nutrient in a number of metabolic pathways. The major symptom of $\mathrm{Fe}$ deficiency is chlorosis as a result of the requirement for $\mathrm{Fe}$ in protochlorophyllide synthesis (Tottey et al., 2003). Fe is essential in reactions that regulate $\mathrm{CO}_{2}$ assimilation and antioxidant protection, and we have shown that Fe-deficient source leaves have

\footnotetext{
Received for publication 12 May 2006. Accepted for publication 24 June 2006. This work was supported in part by the USDA-ARS Northwest Center for Small Fruits Research and the N.Y. Wine/Grape Foundation. The nutrients, lime, and medium used in this study were provided by GreenCare Fertilizers, Miss. Lime, and Conrad Fafard Inc., respectively. We gratefully acknowledge the technical assistance of Scott G.V. Henning and Richard M. Raba.

${ }^{1}$ To whom reprint requests should be addressed; e-mail LC89@Cornell.edu.
}

lower levels of nonstructural carbohydrates and are source-limited (Chen et al., 2004; Smith and Cheng, 2005). In addition, organic acid metabolism is influenced by $\mathrm{Fe}$ status (Abadía et al., 2002).

When Fe deficiency-induced chlorosis occurs, chlorotic leaves can often have same or even higher total Fe levels than healthy green leaves, which has been referred to as the "chlorosis paradox" (Bavaresco et al., 1999; Römheld, 2000). Thus, leaf total Fe concentration is not a good indicator of plant Fe status; instead, "active Fe," extracted with dilute acids or ferrous Fe chelates, correlates better with chlorophyll concentration and leaf function (Chen et al., 2004; Gezgin and Er, 2001; Römheld, 2000).

There are several means for alleviating $\mathrm{Fe}$ chlorosis in grapevines. Grafting scions to high $\mathrm{pH}$ tolerant or "Fe-efficient" rootstocks can be effective in preventing chlorosis (Brancadoro et al., 1995). However, 'Concord' vines are typically grown own-rooted to lower establishment cost. Other methods to control $\mathrm{Fe}$ deficiency include: 1) foliar $\mathrm{Fe}$ sprays, 2) lowering soil $\mathrm{pH}$, and 3) supplementing the soil with $\mathrm{Fe}$ chelates (Tagliavini and Rombolà, 2001). Foliar Fe sprays can be effective but only provide a temporary solution; although lowering soil $\mathrm{pH}$ is the best means to overcome Fe deficiency, it is not always feasible. Ferric chelates applied to the soil can often alleviate chlorosis, but they vary in their stability and effectiveness at high $\mathrm{pH}$. For instance, EDDHA [ethylenediamine di (o-hydroxyphenylacetic)acid] can form a very stable ferric chelate from $\mathrm{pH} 4$ to 9, whereas Fe-EDTA (ethylenediaminetetraacetic acid) is stable only at low $\mathrm{pH}$ and loses its ability to chelate $\mathrm{Fe}^{3+}$ above $\mathrm{pH} 6.5$ (Norvell, 1991).

Fe-EDDHA has been used to alleviate Fe-chlorosis in a variety of crops, yet only a few reports address the use of Fe-EDDHA for correcting Fe-deficiency in Vitis spp. (Gruber and Kosegarten, 2002; Tagliavini and Rombolà, 2001). In addition, most of the published work with Fe nutrition in grapevines is concerned primarily with $V$. vinifera, and little to no information exists regarding the effectiveness of Fe-EDDHA for $\mathrm{Fe}$ correction in $V$. labruscana. Compared with $V$. vinifera, $V$. labruscana has a lower optimum pH (Bates et al., 2002), and the use of Fe-EDDHA to alleviate limeinduced chlorosis in the high $\mathrm{pH}$-sensitive (Fe-inefficient) $V$. labruscana has not been characterized. The objective of this work was to determine if Fe-EDDHA can effectively alleviate chlorosis in 'Concord' grapevines grown at high $\mathrm{pH}$, which will provide a foundation for further research related to the optimum rate and timing of application of Fe-EDDHA in 'Concord' vineyards with calcareous soils.

\section{Materials and Methods}

Own-rooted 1-year-old 'Concord' grapevines were transplanted on 5 May 2005 into 19.8 -L plastic pots containing an $80 \%$ peat : $20 \%$ perlite (v/v) growth medium (Conrad Fafard Inc., Agawam, Mass). Substrate was adjusted to $\mathrm{pH} 7.5$ with $16.3 \mathrm{~kg} \cdot \mathrm{m}^{-3} \mathrm{CaCO}_{3}$ (Grade R2; Mississippi Lime, St. Genevieve, Mo.), and vines were grown outdoors from 17 May 2005 to 29 Sept. 2005. At budbreak, extra shoots were removed and two shoots were allowed to grow on each plant.

Twice weekly, each plant was supplied with $1 \mathrm{~L}$ of a complete nutrient solution, including micronutrients and $0,0.5,1.0,2.0$, or $4.0 \mathrm{mg} \cdot \mathrm{L}^{-1} \mathrm{Fe}$ from Fe-EDDHA (Dissolvine; GreenCare Fertilizers, Chicago). Nutrients were blended as a water-soluble fertilizer based on Hoagland's No. 2 solution by GreenCare Fertilizers and applied at a rate of $\left(\mathrm{mg} \cdot \mathrm{L}^{-1}\right) 210 \mathrm{~N}, 31 \mathrm{P}, 235 \mathrm{~K}, 160 \mathrm{Ca}$, $49 \mathrm{Mg}, 0.50 \mathrm{Mn}, 0.05 \mathrm{Zn}, 0.02 \mathrm{Cu}, 0.01 \mathrm{Mo}$, and $0.49 \mathrm{~B}$. Micronutrient cations were applied as sulfate salts, and solution was supplemented with $80 \mathrm{mg} \cdot \mathrm{L}^{-1} \mathrm{~K}$ from $\mathrm{KCl}$. There were five replicates (three plants per replicate) for each treatment in a completely randomized design. Approximately 9 weeks after planting, one recently mature leaf from each shoot on one plant per rep was selected for midday $\mathrm{CO}_{2}$ assimilation and photosystem II (PSII) quantum efficiency measurements. Selected leaves were then harvested for total $\mathrm{Fe}$, active $\mathrm{Fe}$, and chlorophyll analysis.

Gas exchange was measured with a CIRAS-1 system (PP Systems, Herts, U.K.) at ambient $\mathrm{CO}_{2}\left(360 \mu \mathrm{mol} \cdot \mathrm{mol}^{-1}\right)$ at noon 
under a photon flux density of $1540 \pm$ $68 \mu \mathrm{mol} \cdot \mathrm{m}^{-2} \cdot \mathrm{s}^{-1}$ and a leaf temperature of $29.8 \pm 0.8^{\circ} \mathrm{C}$. Chlorophyll fluorescence was measured with a pulse-modulated fluorometer (FMS2; Hansatech Instruments, Norfolk, U.K.) under the same environmental conditions, and PSII quantum efficiency (proportion of light absorbed by PSII used in photochemistry) was calculated as [maximum fluorescence (Fm') - steady-state fluorescence (Fs)]/Fm' (Genty et al., 1989).

After gas exchange and PSII measurements, chlorophyll was extracted from two $1.2-\mathrm{cm}^{2}$ leaf discs according to (Arnon, 1949). Leaves were then washed in $0.1 \mathrm{~N}$ $\mathrm{HCl}$, rinsed in deionized $\mathrm{H}_{2} \mathrm{O}$, and dried at $70{ }^{\circ} \mathrm{C}$ for $7 \mathrm{~d}$. Dried samples were ground through a $0.5-\mathrm{mm}$ screen using a Cyclotec sample mill.

Active Fe was extracted by shaking $50 \mathrm{mg}$ dried leaf tissue in $1.0 \mathrm{~mL}$ of $0.1 \mathrm{~N} \mathrm{HCl}$ for $24 \mathrm{~h}$. The solution was centrifuged at $10,000 \mathrm{~g}$ for $5 \mathrm{~min}$, and the supernatant was passed through a $0.45-\mu \mathrm{m}$ polyvinylidene fluoride (PVDF) syringe filter. A $500-\mu \mathrm{L}$ aliquot was removed and mixed with $250 \mu \mathrm{L}$ of $500 \mathrm{~mm}$ ascorbic acid and $250 \mu \mathrm{L}$ of $1 \mathrm{~mm}$ bathophenanthroline (BP). The Fe(II)-BP chromophore was developed by raising the $\mathrm{pH}$ to 4.5 with $500 \mu \mathrm{L}$ of $2.5 \mathrm{M} \mathrm{NaOAc-pH} 4.5$ (Diehl et al., [1980]; $100 \mathrm{~mL} \mathrm{NaOAc}$ was decontaminated by adding $2 \mathrm{~mL} 500 \mathrm{~mm}$ AsA, $4 \mathrm{~mL}$ of $1 \mathrm{~mm} \mathrm{BP}$, and $10 \mathrm{~mL}$ 1-octanol and shaking and allowing the layers to separate. The alcohol layer was removed and additional 1-octanol was added and removed until there was no visible color.) Samples were mixed vigorously and allowed to sit for $5 \mathrm{~min}$ before the addition of $400 \mu \mathrm{L}$ of 1-octanol. Solution was mixed again and the $\mathrm{Fe}(\mathrm{II})$-BP complex was moved into the immiscible, 1-octanol phase after settling for $15 \mathrm{~min}$. Samples were centrifuged at $1000 \mathrm{~g}_{\mathrm{n}}$ for $5 \mathrm{~min}$ to promote phase separation. Three hundred microliters of the upper phase (containing $\mathrm{Fe}[\mathrm{II}]-\mathrm{BP}$ in 1-octanol) was transferred to a chemical resistant ultramicrocuvette (BrandTech, Essex, Conn.), capped, and absorbance measured at $535 \mathrm{~nm}$ against an appropriate blank. Fe concentration was calculated from a standard curve using $\mathrm{Fe}$ atomic absorption standard solution (Aldrich Chemical, Milwaukee, Wisc.) in $0.1 \mathrm{~N} \mathrm{HCl}$ and extracting along with samples.

Total $\mathrm{Fe}$ was determined in a similar manner. Fifty milligrams of dried leaf tissue was digested in $\mathrm{HNO}_{3}$ and $30 \% \mathrm{H}_{2} \mathrm{O}_{2}$ according to Jones (1991). Clear digests were brought up to $3.5 \mathrm{~mL}$ with $0.1 \mathrm{~N} \mathrm{HCl}$ and passed through a $0.45-\mu \mathrm{m}$ PVDF syringe filter. Fe was quantified by mixing a $500-\mu \mathrm{L}$ aliquot of the digest with $3.0 \mathrm{~mL}$ of $0.1 \mathrm{~N} \mathrm{HCl}$, $2.0 \mathrm{~mL}$ of $500 \mathrm{~mm}$ ascorbic acid (fresh), and $2 \mathrm{~mL}$ of $1 \mathrm{~mm} \mathrm{BP}$. After mixing over a 5-min period, we added $5 \mathrm{~mL}$ of $5 \mathrm{~m} \mathrm{NaOAc-pH} 4.5$ to develop the chromophore. Solutions were mixed and the Fe(II)-BP complex was moved into the upper phase with the addition of 1 $\mathrm{mL}$ of 1-octanol. Samples were allowed to sit overnight for maximum color formation, remixed, and centrifuged at $1000 \mathrm{~g}_{\mathrm{n}}$ for 5 min. We removed $600 \mu \mathrm{L}$ of the alcohol layer and quantified $\mathrm{Fe}$ as described for active Fe. We also spiked samples with $2 \mu \mathrm{g}$ $\mathrm{Fe}$ before digestion and recovery was $96 \% \pm 3.6 \%$.

At the end of the season, vines were defoliated and total leaf area per pot was determined. Leaves were dried at $70{ }^{\circ} \mathrm{C}$ for $7 \mathrm{~d}$ and the dry weight recorded. We measured the total cane length for both canes per pot and present the data as average cane length per vine.

Analysis of variance and mean comparison was performed using JMP 5.1 (SAS Institute, Cary, N.C.). Means were compared using LSD at $P=0.05$. Nonlinear regression was performed using SigmaPlot 9.0 (Systat Software, Point Richmond, Calif.).

\section{Results}

Leaf total $\mathrm{Fe}$ concentration was similar across most treatments and higher only at the $4.0 \mathrm{mg} \cdot \mathrm{L}^{-1} \mathrm{Fe}$ level when compared with the middle three rates (Fig. 1A). Total Fe concentration in the control leaves was not different from the other treatments. Both active Fe concentration and total chlorophyll concentration increased in response to an increase in the rate of applied Fe-EDDHA (Figs. 1B and 2A). Leaf chlorophyll concentration was significantly correlated with active Fe concentration (Fig. 2B) but not with total $\mathrm{Fe}$ concentration (data not shown).

$\mathrm{CO}_{2}$ assimilation was very low without any supplemental $\mathrm{Fe}$ and increased rapidly in response to $\mathrm{Fe}$ application (Fig. 3A). As applied $\mathrm{Fe}$ increased, $g_{\mathrm{S}}$ increased from 109 to $619 \mathrm{mmol} \cdot \mathrm{m}^{-2} \cdot \mathrm{s}^{-1}$ (Fig. 3B), whereas calculated internal $\mathrm{CO}_{2}$ concentration decreased from 340 to $246 \mu \mathrm{mol} \cdot \mathrm{mol}^{-1}(P<$ 0.001 , data not shown). PSII quantum efficiency was lower in the control plants and increased at rates above $0.5 \mathrm{mg} \cdot \mathrm{L}^{-1} \mathrm{Fe}$ (Fig. $3 \mathrm{C})$. Total leaf area, foliar dry weight, and cane length all increased as Fe application increased to $1 \mathrm{mg} \cdot \mathrm{L}^{-1} \mathrm{Fe}$, but above this rate, a further increase in $\mathrm{Fe}$ did not significantly increase growth (Fig. 4A-C).

\section{Discussion}

This study confirms previous results indicating that foliar total $\mathrm{Fe}$ is not a good measure of Fe nutritional status in 'Concord' grapevines (Chen et al., 2004). Yet why Fe accumulates in chlorotic leaves and paradoxically fails to alleviate chlorosis is not well understood. Most agree that $\mathrm{Fe}$ is transported through the xylem primarily as Fe(III)citrate, and on reaching the leaf apoplast, a leaf plasma membrane bound ferric chelate reductase is required to cleave $\mathrm{Fe}$ from the chelate and reduce it to $\mathrm{Fe}^{2+}$ before transport into the mesophyll cytoplasm (Brüggemann et al., 1993). Mengel (1994) suggests that Fe is immobilized in the leaf apoplast when soil $\mathrm{HCO}_{3}{ }^{-}$or $\mathrm{NO}_{3}{ }^{-}$raises the $\mathrm{pH}$ of the xylem sap and leaf apoplast. There is mixed support for this hypothesis (Nikolic and Römheld, 2002, 2003), and we have found that the $\mathrm{pH}$
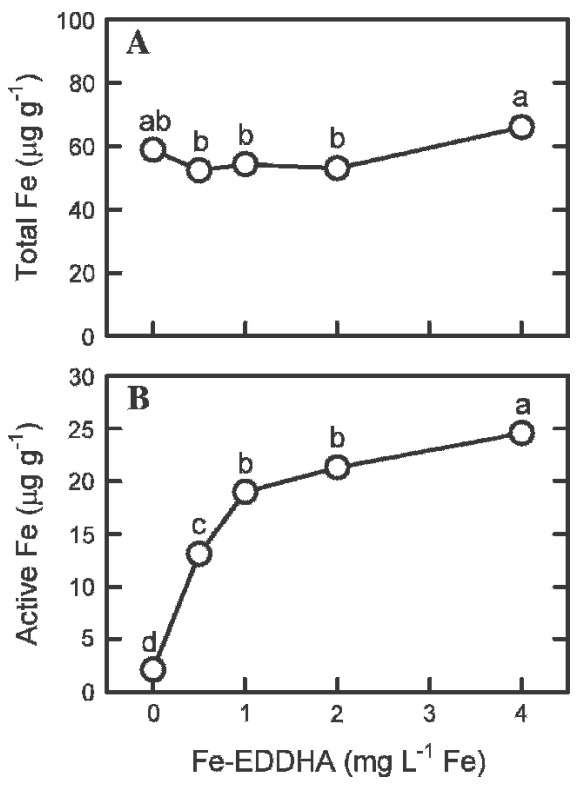

Fig. 1. (A) Total Fe concentration $(P \leq 0.05)$ and (B) active $\mathrm{Fe}$ concentration $(P \leq 0.001)$ of 'Concord' grape leaves in relation to $\mathrm{Fe}$ EDDHA application rate. Leaf Fe concentration is expressed on a dry weight basis. Each point is the mean of five replicates. Means were separated using Tukey's HSD test at $P=0.05$.

of the xylem sap of 'Concord' vines does not change when they are grown in substrate $\mathrm{pHs}$ ranging from 5.2 to 7.6 (Smith and Cheng, unpublished data). Römheld (2000) suggests that the paradox results from environmental factors that cause an inhibition of leaf expansion. This inhibition of leaf expansion causes a decreased dilution of Fe in the leaf and that total Fe content calculated on a per-leaf basis provides a better indicator of Fe status. This may be true, but the same logic should apply to other nutrients, and it still does not fully explain why chlorosis is not alleviated. In our experiment, low Fe supply decreased the total leaf area per vine (Fig. 4A) as well as midseason individual leaf area (data not shown), indicating that the decrease in leaf expansion is the result of Fe deficiency, not some other environmental factor.

What is clear is that when the paradox exists, extracting active Fe provides a better diagnosis of $\mathrm{Fe}$ nutritional status (Figs. 1B and $2 \mathrm{~B}$ ). Active $\mathrm{Fe}$ analysis is generally quantified either by acid extraction from dried leaves followed by determination of total $\mathrm{Fe}$ in the extract by inductively coupled plasma/atomic absorption spectroscopy (ICP/AA) or by extracting $\mathrm{Fe}$ from fresh leaves using $\mathrm{Fe}(\mathrm{II})$-chelates and assaying spectrophotometrically. The ICP/AA method is reliable but can be costly. The traditional $\mathrm{Fe}(\mathrm{II})$-chelate method is less expensive but is not very reliable as a result of a high level of interference, and in many cases, fresh leaves are not readily available. We present a reliable and inexpensive method for quantifying active $\mathrm{Fe}$ in dried leaves using a Fe(II)chelate after acid extraction. By moving the 

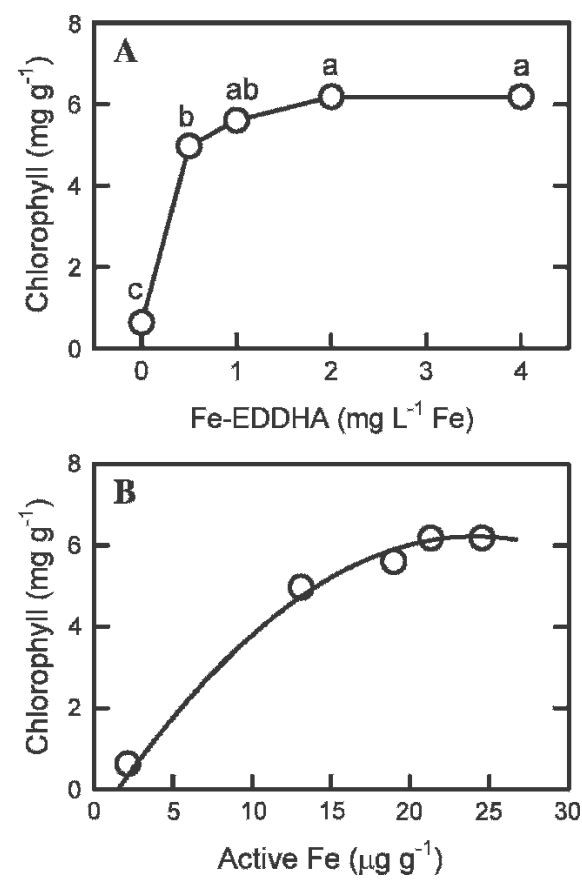

Fig. 2. (A) Total chlorophyll concentration of 'Concord' grape leaves $(P \leq 0.001)$ in relation to Fe-EDDHA application rate and (B) relationship between active $\mathrm{Fe}$ concentration and chlorophyll concentration in 'Concord' grape leaves $(\mathrm{Y}=-0.865+0.588 \mathrm{X}-$ $\left.0.012 \mathrm{X}^{2}, \mathrm{R}^{2}=0.91\right)$. Chlorophyll was extracted from fresh leaves but expressed on a dry weight basis. Each point is the mean of five replicates. Means were separated using Tukey's HSD test at $P=0.05$.

nonpolar $\mathrm{Fe}(\mathrm{II})$-chelate into the upper, immiscible alcohol phase, we can eliminate most interfering compounds by leaving them in the aqueous phase. In addition, we can vary the amount of 1-octanol used so we can concentrate the chromophore and increase resolution and the level of detection.

Leaves of 'Concord' vines grown at high $\mathrm{pH}$ without any supplemental Fe had very low rates of $\mathrm{CO}_{2}$ assimilation (Fig. 3A) and used only a small proportion of the absorbed light in photosynthesis (Fig. 3C). The decrease in $\mathrm{CO}_{2}$ assimilation was not the result of stomatal limitation, because Fe-deficient leaves had a higher calculated internal $\mathrm{CO}_{2}$ concentration compared with the Fe-sufficient leaves. Our previous work showed that the activities of Rubisco and other photosynthetic enzymes were decreased by $\mathrm{Fe}$ deficiency (Chen et al., 2004). A small increase in the rate of applied Fe-EDDHA was very beneficial in increasing $\mathrm{CO}_{2}$ assimilation presumably by overcoming the nonstomatal limitation imposed by $\mathrm{Fe}$ deficiency. This conclusion may seem overly simplistic; however, in a companion experiment in which we grew 'Concord' vines from $\mathrm{pH} 5.2$ to 7.6 without any supplemental $\mathrm{Fe}$, leaves had high levels of chlorophyll and corresponding high rates of $\mathrm{CO}_{2}$ assimilation when the substrate $\mathrm{pH}$ was below 6 . This indicates that there was sufficient available $\mathrm{Fe}$ at low $\mathrm{pH}$ from the peat, perlite, and irrigation water. Yet
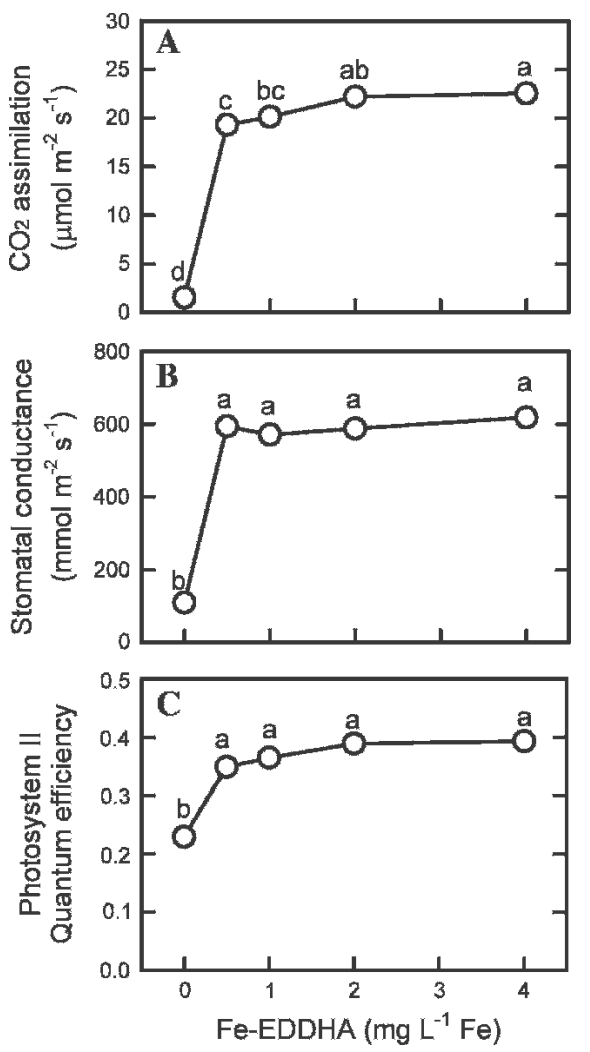

Fig. 3. (A) $\mathrm{CO}_{2}$ assimilation $(P \leq 0.001)$, (B) $g_{\mathrm{S}}$ $(P \leq 0.001)$, and $(\mathbf{C})$ photosystem II quantum efficiency $(P \leq 0.001)$ of 'Concord' grape leaves in relation to Fe-EDDHA application rate. Measurements were taken midday at ambient $\mathrm{CO}_{2}\left(360 \mu \mathrm{mol} \cdot \mathrm{mol}^{-1}\right)$ under a photon flux density of $1540 \pm 68 \mu \mathrm{mol} \cdot \mathrm{m}^{-2} \cdot \mathrm{s}^{-1}$ and a leaf temperature of $29.8 \pm 0.8{ }^{\circ} \mathrm{C}$. Each point is the mean of five replicates. Means were separated using Tukey's HSD test at $P=0.05$.

although there may be sufficient levels of total iron in the soil at high $\mathrm{pH}$, 'Concord' grapevines can readily develop Fe deficiency because of low $\mathrm{Fe}$ solubility. Thus, the addition of Fe-EDDHA is a highly effective chelate for alleviating $\mathrm{Fe}$ chlorosis and increasing $\mathrm{CO}_{2}$ assimilation at high $\mathrm{pH}$ for 'Concord' vines.

Vine growth was very responsive to $\mathrm{Fe}$ EDDHA application. Leaf area and foliar dry weight nearly tripled as Fe-EDDHA increased from 0 to $1.0 \mathrm{mg} \cdot \mathrm{L}^{-1} \mathrm{Fe}$ (Figs. $4 \mathrm{~A}$ and $\mathrm{B}$ ), and cane length per vine also significantly increased (Fig. 4C). Above $1 \mathrm{mg} \cdot \mathrm{L}^{-1}$ $\mathrm{Fe}$, a further increase in $\mathrm{Fe}$ did not significantly increase growth. Our results demonstrate that $1 \mathrm{mg} \cdot \mathrm{L}^{-1} \mathrm{Fe}$ from $\mathrm{Fe}-\mathrm{EDDHA}$ is a critical applied Fe concentration for 'Concord' grapevines grown in containers with a nutrient solution based on an $\mathrm{N}$ concentration of $210 \mathrm{mg} \cdot \mathrm{L}^{-1}$. The critical concentration of applied $\mathrm{Fe}$ is likely to depend on the nitrogen status and overall growth rate.

There is little published information on the use of Fe-EDDHA to correct $\mathrm{Fe}$ deficiency in the vineyard, although it is well known that Fe-EDDHA can effectively cor-
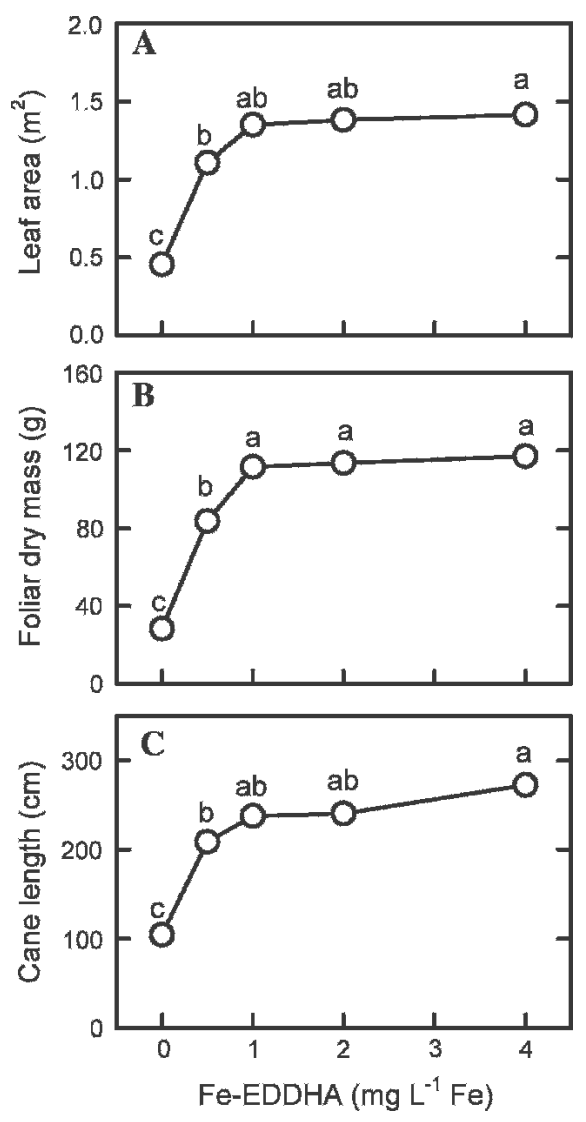

Fig. 4. (A) Total leaf area $(P \leq 0.001)$, (B) foliar dry weight $(P \leq 0.001)$, and $(\mathbf{C})$ cane length $(P \leq 0.001)$ of 'Concord' grapevines in relation to Fe-EDDHA application rate. Data were collected at the end of the growing season. Each point is the mean of five replicates. Means were separated using Tukey's HSD test at $P=0.05$.

rect chlorosis in other crops. Winkler et al. (1974) applied Fe-EDDHA (1 g.m $\left.{ }^{-2}\right)$ to Vitis spp. in the water of a flood irrigation system and were not able to effectively correct chlorosis. They were more successful applying the chelate to dry soil at $15 \mathrm{~g}$ per vine over two seasons. Because it is much easier to prevent $\mathrm{Fe}$ deficiency rather than correct it, it follows that the best strategy would be to apply Fe-EDDHA before budbreak. McEachern (1982) recommend applying one tablespoon Fe-EDDHA per vine in the spring when chlorosis first appears. However, Tagliavini and Rombolà (2001) found that applying $\mathrm{Fe}$ in late summer-early fall was more effective in preventing chlorosis in Actinidia deliciosa when compared with applications in the spring, before budbreak. The optimum rate and timing of FeEDDHA application in 'Concord' vineyards to correct $\mathrm{Fe}$ deficiency-induced chlorosis remains to be determined.

In conclusion, Fe-EDDHA does effectively alleviate Fe deficiency-induced leaf chlorosis in 'Concord' grapevines grown at high $\mathrm{pH}$. The optimum rate and timing of application under vineyard conditions still need to be worked out. Compared with total 
$\mathrm{Fe}$, leaf "active $\mathrm{Fe}$ " better indicates the actual Fe status of 'Concord' vines.

\section{Literature Cited}

Abadía, J., A.F. López-Millàn, A. Rombola, and A. Abadía. 2002. Organic acids and Fe deficiency: A review. Plant Soil 241:75-86.

Arnon, D.I. 1949. Copper enzymes in isolated chloroplasts - polyphenoloxidase in Beta vulgaris. Plant Physiol. 24:1-15.

Bates, T.R., R.M. Dunst, T. Taft, and M. Vercant. 2002. The vegetative response of 'Concord' grapevines to soil $\mathrm{pH}$. HortScience 37:890-893.

Bavaresco, L., E. Giachino, and R. Colla. 1999. Iron chlorosis paradox in grapevine. J. Plant Nutr. 22:1589-1597.

Brancadoro, L., G. Rabotti, A. Scienza, and G. Zocchi. 1995. Mechanisms of Fe-efficiency in roots of Vitis spp. in response to iron deficiency stress. Plant Soil 171:229-234.

Brüggemann, W., K. Maaskantel, and P.R. Moog. 1993. Iron uptake by leaf mesophyll cells-The role of the plasma membrane-bound ferric chelate reductase. Planta 190:151-155.

Chen, L.S., B.R. Smith, and L. Cheng. 2004. $\mathrm{CO}_{2}$ assimilation, photosynthetic enzymes, and carbohydrates of 'Concord' grape leaves in response to iron supply. J. Amer. Soc. Hort. Sci. 129:738-744.

Davenport, J.R. and R.G. Stevens. 2006. High soil moisture and low soil temperature are associated with chlorosis occurrence in Concord grape. HortScience 41:418-422.
Diehl, H., L. McBride, and N. Mohamed. 1980. Bathophenanthroline, p. 7-22. In: The iron reagents G. Frederick Smith Co., Columbus, Ohio.

Genty, B., J.M. Briantais, and N.R. Baker. 1989 The relationship between the quantum yield of photosynthetic electron transport and quenching of chlorophyll fluorescence. Biochim. Biophys. Acta. 990:87-92.

Gezgin, S. and F. Er. 2001. Relationship between total and active iron contents of leaves and observed chlorosis in vineyards in KonyaHadim-Alada region of Turkey. Commun. Soil Sci. Plant Anal. 32:1513-1521.

Gruber, B. and H. Kosegarten. 2002. Depressed growth of non-chlorotic vine grown in calcareous soil is an iron deficiency symptom prio to leaf chlorosis. J. Plant Nutr. Soil Sci. 165:111-117.

Jones, J.B. 1991. Plant tissue analysis in micronutrients, p. 477-521. In: J.J. Mortvedt, F.R. Cox, L.M. Shuman, and R.M. Welch (eds.) Micronutrients in agriculture. Soil Sci. Soc. Amer., Madison, Wisc.

McEachern, G.R. 1982. Texas vineyard guide Texas Ag. Ext. Serv. Bul. 1424:37.

Mengel, K. 1994. Iron availability in plant tissuesIron chlorosis on calcareous soils. Plant Soil 165:275-283.

Nikolic, M. and V. Römheld. 2002. Does high bicarbonate supply to roots change availability of iron in the leaf apoplast? Plant Soil 241: $67-74$.
Nikolic, M. and V. Römheld. 2003. Nitrate does not result in iron inactivation in the apoplast of sunflower leaves. Plant Physiol. 132: 1303-1314.

Norvell, W.A. 1991. Reactions of metal chelates in soils and nutrient solutions, p. 187-227. In: J.J. Mortvedt, F.R. Cox, L.M. Shuman, and R.M. Welch (eds.). Micronutrients in agriculture. Soil Sci. Soc. Amer., Madison, Wisc.

Römheld, V. 2000. The chlorosis paradox: Fe inactivation as a secondary event in chlorotic leaves of grapevine. J. Plant Nutr. 23:1629-1643.

Schofield, E.A. 1988. 'He sowed; others reaped': Ephraim Wales Bull and the origins of the 'Concord' grape. Arnoldia 48:4-15.

Smith, B.R. and L. Cheng. 2005. Photoprotective mechanisms of 'Concord' grape leaves in relation to iron supply. J. Amer. Soc. Hort. Sci. 130:331-340.

Tagliavini, M. and A.D. Rombolà. 2001. Iron deficiency and chlorosis in orchard and vineyard ecosystems. Eur. J. Agron. 15:71-92.

Tottey, S., M.A. Block, M. Allen, T. Westergren, C. Albrieux, H.V. Scheller, S. Merchant, and P.E. Jensen. 2003. Arabidopsis CHL27, located in both envelope and thylakoid membranes, is required for the synthesis of protochlorophyllide. Proc. Natl. Acad. Sci. U S A 100:1611916124

Winkler, A.J., J.A. Cook, W.M. Kliewer, and L.A. Lider. 1974. Fertilizer elements required by the vine, p 410-434. In: General viticulture. Univ. Calif. Press, Berkeley. 